\title{
Social status and behavioral observations of children exhibiting comorbid anxiety and ADHD symptoms
}

Daniel B. Chorney

West Virginia University

Follow this and additional works at: https://researchrepository.wvu.edu/etd

\section{Recommended Citation}

Chorney, Daniel B., "Social status and behavioral observations of children exhibiting comorbid anxiety and ADHD symptoms" (2006). Graduate Theses, Dissertations, and Problem Reports. 2448.

https://researchrepository.wvu.edu/etd/2448

This Thesis is protected by copyright and/or related rights. It has been brought to you by the The Research Repository @ WVU with permission from the rights-holder(s). You are free to use this Thesis in any way that is permitted by the copyright and related rights legislation that applies to your use. For other uses you must obtain permission from the rights-holder(s) directly, unless additional rights are indicated by a Creative Commons license in the record and/ or on the work itself. This Thesis has been accepted for inclusion in WVU Graduate Theses, Dissertations, and Problem Reports collection by an authorized administrator of The Research Repository @ WVU. For more information, please contact researchrepository@mail.wvu.edu. 
Social Status and Behavioral Observations of

Children Exhibiting Comorbid Anxiety \& ADHD Symptoms

Daniel B. Chorney

\author{
Thesis submitted to the \\ Eberly College of Arts and Sciences \\ at West Virginia University \\ in partial fulfillment of the requirements for \\ the degree of
}

Master of Science

in

Psychology

Tracy L. Morris, Ph.D., Chair

Matthew H. Scullin, Ph.D.

Julie H. Patrick, Ph.D.

Department of Psychology

Morgantown, West Virginia

2006

Keywords: Sociometrics, ADHD, child anxiety, comorbidity, peer rejection, peer neglect 


\section{ABSTRACT \\ Social Status and Behavioral Observations of Children Exhibiting Comorbid Anxiety \& ADHD Symptoms}

\section{Daniel B. Chorney}

The development of strong and positive relationships early in childhood is key to later social adjustment. Many behaviors have been shown to be related to children's status among their peers, defining whether they will be seen as popular, rejected, neglected, controversial, or of average status in the child's peer group. Children who display anxious behaviors are often overlooked by their peers, while aggressive and disruptive behaviors can lead to rejection. A small proportion of students display both symptoms of anxiety and ADHD, and prior research fails to show what peer status group most represents these children, or what social interaction skills these children display in a school setting. This study investigated the peer social status of children who display anxious, ADHD, and comorbid behavioral patterns. To further understand the characteristics of these different types of children, playground observations were made to attempt to reveal the proportion of positive, negative, and solitary play exhibited by each group during freeplay interaction with peers in their school environment. Results indicated no significant difference between groups on sociometric status or freeplay behavior. Limitations and future directions are discussed. 


\section{Acknowledgements}

I am truly indebted and grateful for the support I received from friends, family, and colleagues during this project. Although there are many to thank, some stand above.

My family - Alice, Julia, and Michael - without you I would not be the person I am today. Thank you with all my heart.

My friends - Jill MacLaren and Josh Masse - you are both there for me when I need you most, when no one else will listen, when I am at my worst. I cannot thank you enough.

A simple thank you is not enough for my advisor and committee chair, Dr. Tracy Morris. I could not imagine going through this process without her, and I am always inspired by the courage, kindness, and determination she displays at all times. I am truly grateful for all of your help and for believing in me. Thank you Tracy. 


\section{Table of Content}

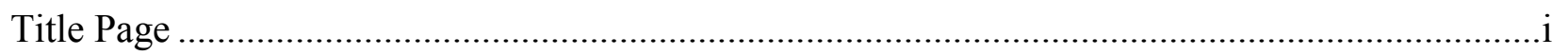

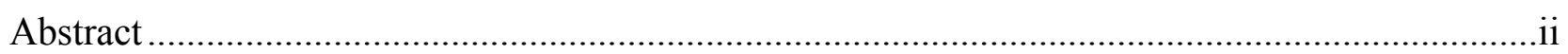

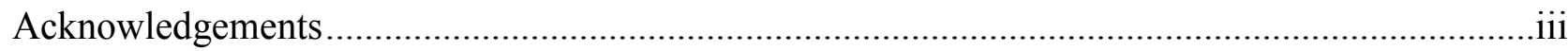

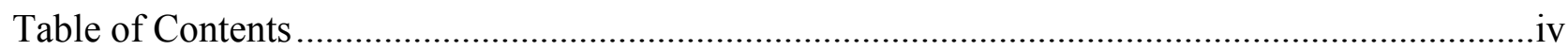

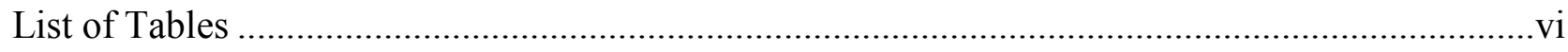

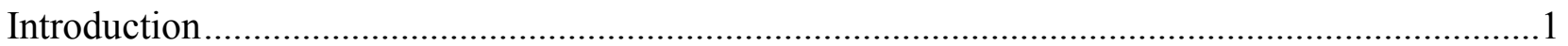

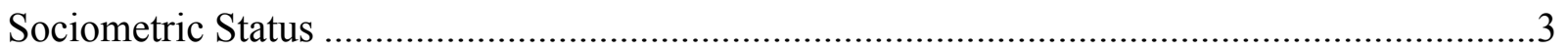

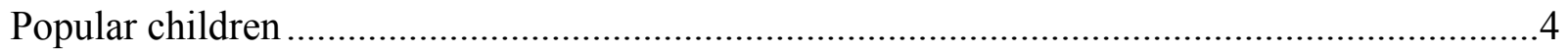

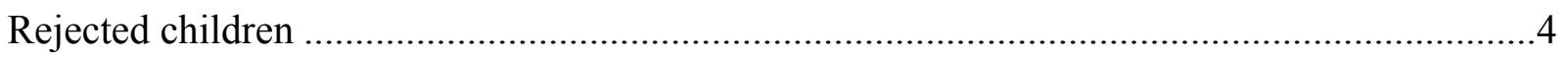

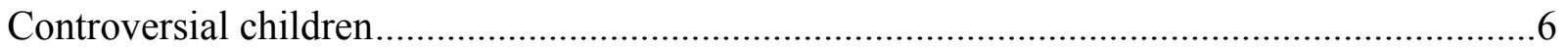

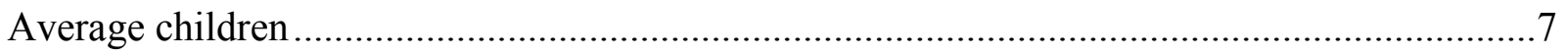

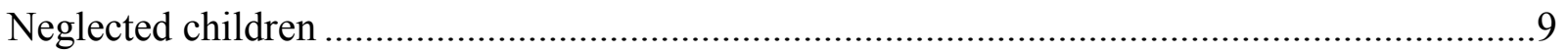

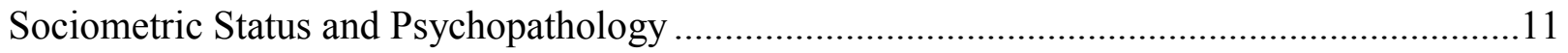

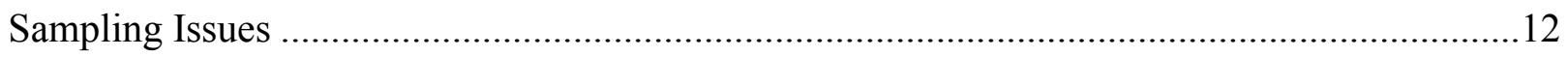

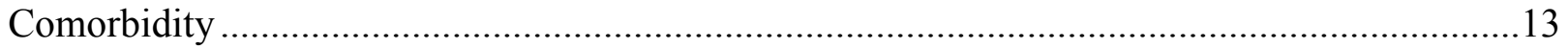

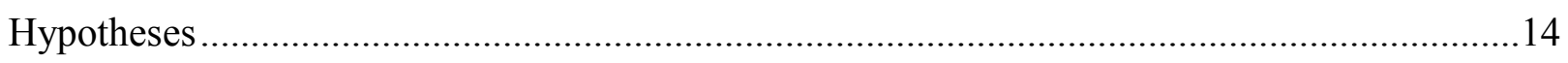

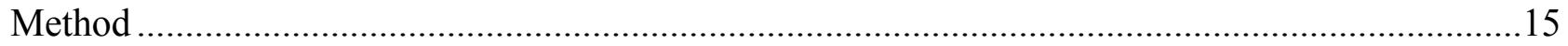

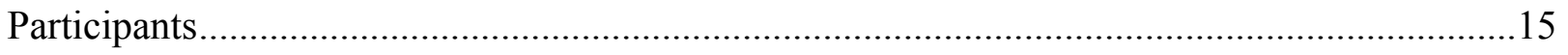

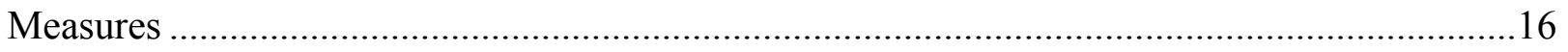

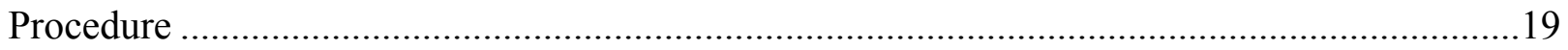

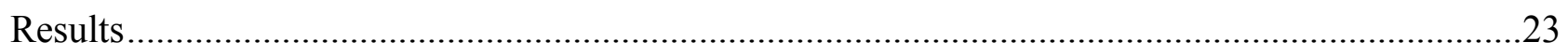

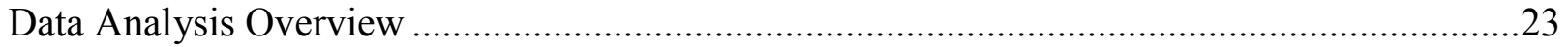




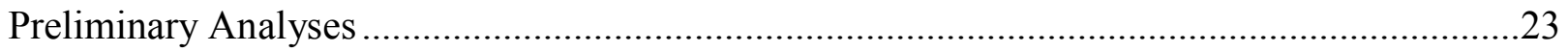

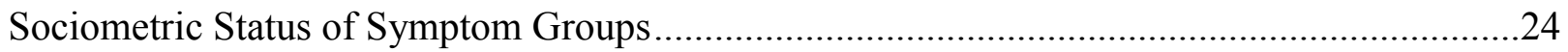

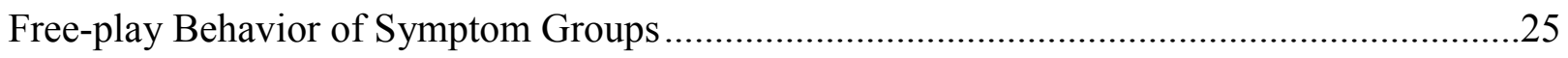

Follow-up Tests on Freeplay Behavior of Symptom Groups .............................................25

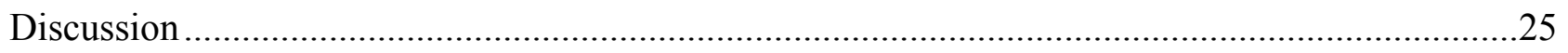

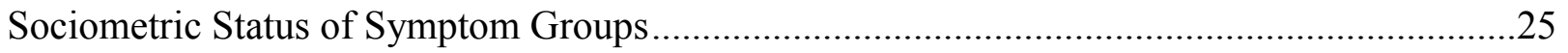

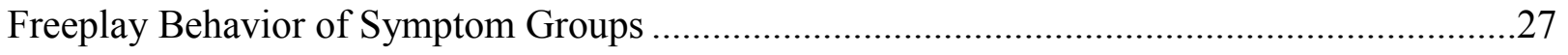

Limitations and Future Directions .............................................................................28

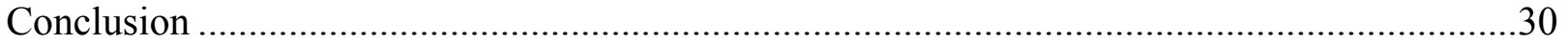

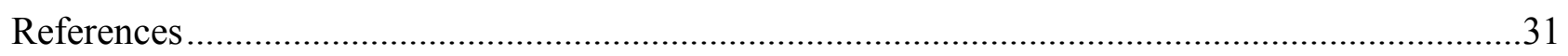




\section{List of Tables}

Table 1. Symptom Group Distribution Across Sociometric Status........................................40

Table 2. One-Way Analyses of Variance for Effects of Age, Gender, and Grade......................41 on Consent Rate

Table 3. Means and Standard Deviations on Entire Sample for Anxiety.......................42 and ADHD Measures

Table 4. Means and Standard Deviations on Final Sample for Anxiety and....................43 ADHD Measures

Table 5. Kruskal-Wallis Test of Behavior Rates in Freeplay Observation.....................44 
Social Status and Behavioral Observations of Children Exhibiting Comorbid Anxiety \& ADHD Symptoms

The development and maintenance of peer relationships in childhood is central to social development and growth (Hartup, 1989). A child's friends can serve many functions in his or her life, at times being trusted allies, and at other times harsh critics during a child's progression through their physical and mental developmental milestones. Early theorists put forward the belief that interaction with intimate friends during childhood and adolescence provides the best foundation for satisfying, close relationships later in life (Sullivan, 1953), and that these experiences provide the opportunities necessary for the development of social competence (Hartup, 1989). On the whole, seven friendship functions appear with some regularity across various formulations: a) fostering the growth of social competence, b) serving as sources of ego support and self-validation, c) providing emotional security in novel or potentially threatening situations, d) serving as sources of intimacy and affection, e) providing guidance and assistance, f) providing a sense of reliable alliance, and g) providing companionship and stimulation. (Asher \& Parker, 1989).

As children grow, their friendships change and develop over time as well. Social status, however, is established quickly when children are placed in groups, even with totally unfamiliar peers (Coie \& Kupersmidt, 1983). The importance then, of intervening with children who may have a propensity to fall into neglected or rejected status among their peers should be of major concern to those involved in school settings and mental health professions. The social problems these children experience may not merely be the result of circumstances or chance; there appears to be something about these children's behavior that produces similar results across totally distinct social settings (Coie \& Kupersmidt, 1983). Although behaviors often change as a result 
of context and environment, children's behavior in peer groups is stable enough across time and settings (Cillessen, Bukowski, \& Haselager, 2000) to predict their sociometric status quickly and accurately after relatively few interactions with a new group.

When discussing the initial emergence of social status, a question of interest is whether children's overt behavioral characteristics lead to their status within the group, or whether their behavior is a consequence of their status. Basically, do behaviors define status or does status define behavior? Children's early behavioral tendencies can contribute and lead to their eventual acceptance or rejection from the group (Ladd, Price, \& Hart 1988), although some have hypothesized that a child's behavior may be the result of frustration or anger from being confined or positioned within a certain group, and their overt behavior is a natural response to their environment. More recent research (Keane \& Calkins, 2004) appears to support the hypothesis that specific behaviors within the peer group account for and are predictive of peer status.

Regardless of the way in which social status develops, the consequences of children's acceptance or rejection within peer groups are numerous and important to consider. Research has shown strongest support for ties between rejected peer status and future maladjustment, with general support for the hypothesis that children with poor peer adjustment are at risk for later life difficulties (Coie, 1990; DeRosier \& Thomas, 2003; Parker \& Asher, 1987; Ollendick, Weist, Borden, \& Greene, 1992). With respect to proportions, $28 \%$ to $70 \%$ of adults with psychological disorders show a history of problematic peer relationships (Parker \& Asher, 1987).

There has been some controversy over which method of defining sociometric status in children is most appropriate and ethical for use with the given population. Four major methods currently exist: peer-nomination based categorical systems (Coie, Dodge, \& Coppotelli, 1982), 
peer-rating based systems (Asher \& Dodge, 1986; Asher, Singleton, Tinsley, \& Hymel, 1979), absolute frequency of nominations (Newcomb \& Bukowski, 1983), and a unidimensional ratingscale system (Ladd, 1983). Peer-nomination based and peer-rating systems are by far the most prominent and widely used systems available today, although there is no one best method to use, and no one system should be used for all research purposes (Terry \& Coie, 1991). Ethical questions were once raised concerning the use of sociometric measures, specifically negative nomination procedures (Asher \& Dodge, 1986; Asher \& Hymel, 1981; Foster \& Ritchey, 1979). Concern was raised as there was a belief that asking children to name peers whom they do not like or with whom they do not like to play would implicitly sanction the saying of negative things about others and even cause children to view disliked peers even more negatively. Since then, however, numerous studies have indicated that sociometric testing does not appear to adversely influence children's peer interactions (Hayvren \& Hymel, 1984; Bell-Dolan, Foster, \& Sikora, 1989; Bell-Dolan \& Wessler, 1994; Iverson \& Iverson, 1996; Iverson, Barton, \& Iverson, 1997).

Sociometric Status

Past research has identified five major sociometric status groups: popular, rejected, neglected, average, and controversial. Each presents with a relatively distinct behavioral profile (Newcomb, Bukowski, \& Pattee, 1993). These groups are formed through the use of peer nomination procedures, which has children identify three peers they like to play with the most, and three children they like to play with the least. With respect to nominations, popular children receive a high proportion of positive nominations and low proportion of negative nominations, while rejected children receive the highest proportion of disliked nominations and low proportions of negative nominations. Neglected children receive few, if any, positive or negative 
nominations and are relatively ignored by the group, while controversial children receive high proportions of both positive and negative nominations. Average children receive a moderate amount of both positive and negative nominations, creating a residual group of children who are neither popular nor rejected by peers.

\section{Popular Children}

Numerous studies have examined which behaviors are most associated with a child's given status. Popular children demonstrate the most prosocial behavior, and often receive descriptions such as "cooperates," and "leader," while receiving low scores for descriptors such as "disrupts," "fights," and "seeks help." (Coie, Dodge, \& Coppotelli, 1982; Coie \& Kupersmidt, 1983). Popular boys engage in more active social interaction and less solitary activity than neglected boys (Coie \& Kupersmidt, 1983). Some of their behaviors which reflect leadership qualities include reminding others of the rules, providing suggestions and directions in ambiguous or difficult situations, and establishing the norms for the group (Coie \& Kupersmidt, 1983). It is interesting to note that once popular status is obtained, it may not be that difficult to maintain. Popular boys are much less likely to be a target of aversive behavior than are other boys, thus making it easier for them to stay popular since the child who is untormented by peers is less likely to be provoked to behave inappropriately or aggressively (Coie \& Kupersmidt, 1983). Popular boys have fewer academic problems than average status boys (Coie \& Dodge, 1988).

\section{Rejected Children}

Rejected children display profiles nearly opposite in characteristics to popular children. Whereas popular children are described as cooperative and leaders, rejected children receive low ratings on these items and high ratings on "disrupts the group," "fights," and "seeks help." (Coie, 
Dodge, \& Coppotelli, 1982; Coie \& Kupersmidt, 1983) Rejected boys are highly interactive with others, talkative, highly aversive both verbally and physically, react aggressively when confronted by aversive behavior, and maintain similar behaviors in familiar and unfamiliar groups (Coie \& Kupersmidt, 1983). Although aggression is frequently cited as a cause of rejection, not all rejected children are aggressive and not all aggressive children are rejected (Coie, Dodge, Terry, \& Wright, 1991). Rejected boys display more solitary inappropriate behavior and engage in less parallel play than the other three groups, and are less likely to stay at work or play with the rest of the group during structured activities (Coie \& Kupersmidt, 1983). They also are more likely to be involved in off-task or context inappropriate behavior (Coie, Dodge, \& Coppotelli, 1982). This frequent off-task and solitary behavior of rejected boys may be the consequence, rather than cause, of their rejected status (Coie \& Kupersmidt, 1983; Dodge, 1983). Of all status groups, rejected children display the highest level of social status maintenance across groups and situations (Coie \& Dodge, 1983; Coie \& Kupersmidt, 1983). Even with mixed-sex peer groups at the preschool level, children who displayed arguing behaviors early in the school year maintained their negative reputations, even after changing their negative behavior over the course of the school year (Ladd, Price, \& Hart 1988). Rejected children also report greater feelings of loneliness and social dissatisfaction (Asher \& Wheeler, 1985 ) and have the most academic problems of all the groups (Coie \& Dodge, 1988). Teachers report they have more conduct problems, aggression, and motor excess and attentional problems than their popular counterparts, along with higher levels of conduct disturbance and substance abuse, failing of more grades, and higher likelihood of dropping out of school and committing delinquent offenses (Ollendick, Weist, Borden, \& Greene, 1992). 
The aggressive behaviors which lead to rejection can be broken into two groups: instrumental and relational. Both overt and relational aggression significantly predict aspects of future social adjustment for both boys and girls, but it is the level of relational aggression (i.e., attempts to damage another's relationships) which provides unique information about adjustment and negative changes in adjustment for girls only. Thus, relationally aggressive girls become more rejected over the course of the school year by their peers (Crick, 1996). Instrumental rejection in boys is highly predictive of peer rejection (Coie, Dodge, Terry, \& Wright, 1991). Other gender differences in the profiles of rejected children have been found. Strong learning and achievement difficulties and self-reported peer relationship problems have been to shown to be common characteristics of most rejected children, while interpersonal behavior problems (i.e., aggressive and antisocial patterns) may be a distinguishing characteristic of rejected boys while intrapersonal behavior problems such as being shy/isolated or unhappy, and negative selfconcept with reported parental disappointment may be distinguishing characteristics of rejected girls (Hatzichristou \& Hopf, 1996).

\section{Controversial}

Of all groups, controversial children show the greatest variability within their nomination scores, receiving many positive and negative nominations, with peers having highly variable perceptions of children in this group (Bukowski \& Newcomb, 1985). Controversial children are a unique group as their relationships with some children can be very positive, whereas with others they are perceived as negative and dislikable.

Controversial children are similar to rejected children in that they often are perceived as being disruptive and starting fights, along with engaging in help-seeking behaviors. At the same time, these children also are perceived as being leaders in the peer group, a descriptor associated 
with popular children (Coie, Dodge, \& Coppotelli, 1982). Controversial children are similar to average children in terms of perceived level of cooperation, whereas rejected children as described as actually being un-cooperative. Controversial children score significantly below the mean on shyness, supporting the view that they are visible, active, and assertive children (Coie, Dodge, \& Coppotelli, 1982). The peer description of controversial children is a blend of the description provided for popular and rejected children. They are not shy, act as leaders, act somewhat cooperatively, and yet they display actively antisocial behavior associated with rejected children, engage in help seeking, and display the highest ratings for disrupting the group, starting fights, and having the highest levels of aggression among all five groups (Coie,

Dodge, \& Coppotelli, 1982, Coie \& Dodge, 1988; Newcomb, Bukowski, \& Pattee, 1993). According to teacher ratings, controversial boys do well academically despite being off task when they should be doing work (Coie \& Dodge, 1988). These ratings also show controversial children are not displaying antisocial behavior or having any significant academic difficulties (Hatzichristou \& Hopf, 1996). Teachers view controversial children as less conduct disordered than rejected children, and they are also less likely to drop out of school when compared to this group. Controversial children do share similarities with rejected children, in that they are also likely to fail at least one grade and commit similar numbers of delinquent offenses (Ollendick, Weist, Borden, \& Greene, 1992).

\section{Average Children}

An average status group has been identified in order to provide a reference group with whom the more extreme groups could be compared. These children are neither popular nor rejected, but unlike the neglected group who receives few, if any, nominations, average children receive moderate proportions of both positive and negative nominations (compared to 
controversial children, who receive high proportions of both.) These children generally display a normative pattern of peer relations, being liked by some peers while also disliked by certain peers as well. They differ from other classification groups in that their scores are not nearly as extreme as any of the other status groups since they do not receive high proportions of either high or low nominations, while at the same time they do receive nominations on both sides of the spectrum, making them more prominent members of the peer group in comparison to neglected children.

The average status group shows some heterogeneity within their sociometric classification. A meta-analysis conducted by Newcomb, Bukowski, and Pattee (1993) found that average status children did not differ from rejected children on levels of withdrawal when observation was used as the only information source. Additionally, average status children did not differ on levels of physically aggressive behavior when compared to popular children. These findings may suggest that average status children display some of the characteristics of rejected children, however the same meta-analysis indicates that average status children have higher levels of social and cognitive skills (Newcomb, Bukowski, \& Pattee) and do not use aggression as their primary source of interaction (Williams \& Gilmour, 1994) as compared to children in the rejected status group.

Further comparisons between average status children and others showed that in comparison to the neglected status group, adult reports show no significant differences between average status group children and neglected children on three broadband categories (aggression, sociability, and withdrawal; Newcomb, Bukowski, \& Pattee, 1993). Although these two groups show many similarities and there exists some controversy regarding the utility of having an average status group (French \& Waas, 1985; Rubin, LeMare, \& Lollis, 1990), enough patterns of 
behavioral differences exist to validate the existence of separate, distinct groups of average and neglected status children (Newcomb, Bukowski, \& Pattee, 1993).

\section{Neglected Children}

It is important to make the distinction between children who are actively disliked by their peers (i.e., rejected children) and those who are simply not nominated by their peers as either liked or disliked, such as the case with neglected children (Coie, Dodge, \& Coppotelli, 1982). Neglected boys are the least interactive socially of all groups, not very talkative, rarely behave aversively, and are more likely to withdraw from the scene or ignore the act when confronted with aversive behavior, and they are generally avoidant of aggressive interactions (Coie \& Kupersmidt, 1983; Coie \& Dodge, 1988). Behavioral descriptions of neglected children have shown that they rate very low on scales of cooperation, disruption of group activities, likelihood of fighting, leading peers, or engaging in help-seeking behaviors. Of all five sociometric groups, children in the neglected group score highest on ratings of shyness and overall have low visibility among peers (Coie, Dodge, \& Coppotelli, 1982). More recent research has shown that neither peers nor teachers consider neglected children as being shy/withdrawn, although this may be due to the low visibility of this group which makes it difficult for teachers and/or peers to accurately detect subtle differences in their behavior patterns (Hatzichristou \& Hopf, 1996).

Although generally thought of as shy, children in this neglected group have shown that they are able to depart from their usual social patterns in new group circumstances and can come across as more assertive (Coie \& Kupersmidt, 1983). The presence of familiar peers seems to hold neglected boys to their old social patterns, behaviors which maintain their social status.

The terms shy and withdrawn are often used interchangeably in the literature, and although there is some overlap in definition it is more appropriate to specify exact meanings 
when using these terms to describe behaviors associated with neglected children. Shyness usually implies nonassertive behavior and infrequent interaction (Parker \& Asher, 1987), and shyness in itself is not correlated with rejection or acceptance (Coie, Dodge, \& Coppotelli, 1982). Withdrawal, however, can come about as a result of being anxious, apprehensive, or nonresponsive or even exhibiting bizarre, autistic-like thoughts and behavior. Children who are unresponsive and avoidant or who display unusual types of behavior are likely to be far more aversive to peers than a child who simply infrequently socializes and is nonassertive in mannerisms (Parker \& Asher, 1987).

Importantly, there is some evidence that shyness and withdrawal may be both an antecedent (Rubin, Daniels-Beirness, \& Hayvren, 1982) and consequence (Dodge, 1983) of peer status. In some respects, neglected children's lack of visibility within the classroom and peer group may make it difficult even for their peers to reach a consensus about naming them shy (Coie, Dodge, \& Coppotelli, 1982). Perhaps peer assessments of neglected children tell us nothing definitive about the behavior of neglected children except that they rarely come to their peers' minds (Coie \& Dodge, 1988). Some evidence, however, points to the idea that peer rejection of withdrawn children is age dependent. While still in early childhood, withdrawal from the peer group does not lead to rejection (Ladd \& Burgess, 1999) although by middle childhood, this withdrawal may be perceived as deviant (Rubin, LeMare, \& Lollis, 1990) and these children who withdraw may become rejected.

Research has shown that children who meet criteria for anxiety disorders are liked significantly less than normal children, receive lower social-impact scores (total like-most and like-least nominations), and are most likely to fall in the socially neglected category of peer status (Strauss, Lahey, Frick, Frame, \& Hynd, 1988). These children were liked as infrequently 
as children with conduct disorders (who are most likely to fall into the rejected status group), which highlights the social difficulties of anxious and neglected children.

\section{Sociometric Status and Psychopathology}

Overall, the relation between early peer relationships and later risk for psychopathology seems to be supported by research. These links appear to be strongest for peer rejection and later risk of adolescent externalizing problems (Coie, Terry, Lenox, \& Lochman, 1995; Laird, Jordan, Dodge, Petit, \& Bates, 2001; Parker \& Asher, 1987; Williams \& Gilmour, 1994). These findings also carry over into adolescence and have an impact on internalizing disorders, as both neglected and rejected children continue to report greater social anxiety than any other peer status group (Inderbitzen, Walters, \& Bukowski, 1997).

Despite reported associations among poor peer relationships, social withdrawal, and psychological impairment, issues regarding the actual risk status of peer neglected children have been raised (e.g., Cantrell \& Prinz, 1985, Parker \& Asher, 1987; Rubin, Hymel, LeMare, \& Rowden, 1989). Despite these concerns, a review of the literature does reveal support for the link between neglected status children and future-risk, most frequently internalizing disorders (Strauss et al., 1988; Inderbitzen et al., 1997; LaGreca \& Stone, 1993). In a 21 -year longitudinal study to investigate links between anxious/withdrawn behavior in children and the risk of developing internalizing disorders in adolescence and adulthood, Goodwin, Fergusson, and Horwood (2004) found strong associations between early withdrawn behavior and increased rates of social phobia, specific phobia, and major depression in both adolescence and early adulthood. These findings were apparent even after statistically controlling for a variety of possibly confounding factors (e.g. childhood physical or sexual abuse, parental depression/anxiety, and adverse family life events among others). 


\section{Sampling Issues}

Deciding when and where to sample sociometric data is an important aspect of data collection to take into consideration. Both interpretation and generalization of findings can be affected by what sample population is studied. Drawing one's sample from a school population allows for the widest generalization of findings, as the only criterion for inclusion is attendance at a school at the time of assessment. Unlike clinical samples, where perhaps only the most extreme cases of behavior are seen, a school sample allows for observation of a more broad spectrum of behaviors and disorders to be present. School samples also provide the widest range of variability with respect to acceptance and related behaviors (Parker \& Asher, 1987) and have a more heterogenous sample compared to clinical samples. Clinical samples tend to be more homogenous, as these children are often less skilled socially, have poorer peer adjustment, show lower achievement, and have lower self-esteem than non-referred children (Achenbach \& Edelbrock, 1981; DeApodaca \& Cowen, 1982). The disadvantage to conducting the study with a school population is the relatively low proportion of severe disorders present within the school population (relative to samples drawn from clinical populations), thus a large sample is often needed to find adequate numbers of children with the behavior one is interested in studying.

There are limits to sociometric sampling, as not all possible peers in a child's social network may be available for nomination or available to nominate them. Since acceptance is typically assessed only among classmates, it is possible that some children identified as unpopular do, in fact, have friends in other settings (Parker \& Asher, 1987). 


\section{Comorbidity}

Anxiety disorders and Attention-Deficit Hyperactivity Disorder are the two most common presenting conditions of childhood, and comorbidity between the two is common. Approximately $25-35 \%$ of children diagnosed with ADHD have a comorbid anxiety disorder, such as generalized anxiety disorder, separation anxiety, and social anxiety disorder. Secondary analyses of the Multimodal Treatment Study of Children with ADHD (MTA) suggest that the clinical presentation of ADHD differs in children with ADHD plus a comorbid externalizing disorder versus those with comorbid anxiety disorders. Children with ADHD plus comorbid Oppositional Defiant Disorder (ODD) or Conduct Disorder (CD) tend to be more impulsive, while those with a comorbid anxiety disorder display more inattentive than impulsive characteristics (Newcorn et al., 2004). Children with comorbid ADHD and anxiety report more overall school problems than children with ADHD alone (Biederman, Faraone, \& Chen, 1993), although they do not differ on academic performance (Biederman, Newcorn, \& Sprich, 1991).

Research on the behavioral characteristics of comorbid ADHD/anxiety children has yielded mixed findings. Pliszka $(1989 ; 1992)$ has shown that children with comorbid ADHD/anxiety disorders are less likely to display impulsive/hyperactive behaviors than children with ADHD alone. ADHD-only children also have been shown to be more off-task and disruptive than comorbid children, and this last group was only slightly more disruptive than a control group (displaying neither ADHD nor anxiety). Other studies have shown that the presence of comorbid anxiety disorder is not associated with behavioral suppression, and that behavior rates of children with comorbid ADHD/anxiety are equivalent to those of children with ADHD (using the Classroom Observation Code, Abikoff \& Gittelman, 1985), which contradicts the presumed inhibitory effects of anxiety in children with ADHD (Abikoff et al., 2002). 
Importantly, many of the difficulties these comorbid groups face have lasting effects. The presence of comorbid anxiety and ADHD has been shown to predict impairment in social functioning, withdrawal, delinquency, and aggression on adolescent follow-up (4-9, average 6.8) years later (Newcorn et al., 2004). Additionally, when children display a combination of three disorders, ADHD, conduct disorder and anxiety disorders, they present with the highest level of impairment (as measured by parent CBCL scores), with highest mean scores in domains of social problems, attention problems, anxiety, aggression, and externalizing problems. (Newcorn et al., 2004).

\section{Hypotheses}

1) Based on prior research (Inderbitzen et al., 1997; LaGreca \& Stone, 1993; Strauss et al., 1988), it was expected that children who displayed high levels of anxiety (High Anxiety symptom group) would fall into the neglected status group and children who displayed high levels of disruptive behavior and attention problems (High ADHD symptom group) would predominantly fall into the rejected status group. No prior research has directly examined the sociometric status of children who display high levels of both anxiety and ADHD symptoms.

2) It was expected that children in the comorbid Anxiety/ADHD group would receive a higher proportion of negative peer nominations. Disruptive behaviors, which are strongly correlated with rejected status, would likely overshadow characteristics of anxiety (i.e., disruptive behavior is viewed as more salient to peers than is the behavioral avoidance characteristic of anxiety) thus placing comorbid children at increased risk for rejection from classmates and peers. 
3) Given the withdrawn behavior typically associated with children who endorse symptoms of anxiety, it was hypothesized that children in the High Anxiety symptom group would display the highest proportion of Solitary behavior.

4) Children who tend to be more impulsive and aggressive (High ADHD symptom group) were expected to display the highest proportion of Negative behavior exhibited during free-play observations.

5) It was also hypothesized that children in the Comorbid symptom group would display higher rates of negative behavior during free-play observations.

\section{Participants}

\section{Method}

The initial sample consisted of 638 children enrolled in grades three though five in three local elementary schools participating in a school-based assessment and intervention program. Children ranged in age from 8-12 years old, with a mean age of 9.4 years $(\mathrm{SD}=.91)$. Of the 638 children, 422 consented to participate (66\%), 220 of whom were girls (52.1\%) and 202 were boys (47.9\%). Recruitment was achieved by sending consent forms home with children's report cards at the beginning of the spring semester. Assent was obtained from the children whose parents agreed to participate in the study, and all children were clearly told that their participation was voluntary and they had the right to withdraw participation at any time.

The final sample contained 66 children ranging in age from 8 to 10 years old and drawn from three Morgantown, West Virginia elementary schools participating in a school-based assessment and intervention program. The mean age of the children in the final sample was 9.08 $(\mathrm{SD}=.71)$ years old, and the children were evenly distributed across the third and fourth grades. No children from the fifth grade were included in the final sample. There was a relatively even distribution of girls with 32 (48.5\%) participating and 34 boys (51.5\%) participating. 
Parental consent was obtained for all students participating in the study. The sample reflects the ethnic proportions of the public school system in Morgantown, West Virginia. Child Self-Report Measures

Social Phobia and Anxiety Inventory for Children (SPAI-C). The SPAI-C (Beidel, Turner, \& Morris, 1995; 1998) is a 26-item self-report questionnaire designed to assess social anxiety symptoms in children and adolescents between eight and fourteen years of age. Responses are made on a 3-point Likert-type scale, ranging from 0 (Never, or Hardly Ever) to 2 (Most of the Time, or Always). Twelve items on the measure have sub-items which measure the amount of distress experienced with three different groups of individuals (boys or girls I know, boys or girls I don't know, and adults). Scoring the SPAI-C involves calculating a mean for each of the items which require multiple responses (e.g. a question which has multiple components to it), and a total score is calculated by summing ratings across the 26 items, with a maximum score being 52 .

Beidel, Turner, and Fink (1996) have shown the SPAI-C can effectively differentiate children with social anxiety disorder from normal control children and from children with externalizing disorders such as conduct disorder, oppositional defiant disorder, or attentiondeficit hyperactivity disorder. Using discriminative function analysis, the discriminant function was significant, $\chi^{2}(2, N=128)=48.7, p<.00005$, with $83 \%$ of social phobic children correctly classified (sensitivity $=.80$ ) along with $54 \%$ of normal controls and $40 \%$ of the children with externalizing disorders. Additionally, $19 \%$ of normal controls and $20 \%$ of children with externalizing disorders were misclassified as socially phobic. Cronbach's alpha was calculated as measure of internal consistency, with an alpha-coefficient of .92. Investigation of external and discriminative validity has shown that the SPAI-C can effectively differentiate between social 
anxiety and other anxiety disorders (Beidel, Turner, Hamlin, \& Morris, 1998), and the measure has shown good concurrent validity with the Social Anxiety Scale for Children - Revised (SASC-R), with an overall classification correspondence of 63\% (Morris \& Masia, 1998). Multidimensional Anxiety Scale for Children (MASC). The MASC (March, Parker, Sullivan, Stallings, \& Conners, 1997) is a 39-item rating scale designed to assess four domains of anxiety (1) physical symptoms (tense/restless and somatic/autonomic), (2) social anxiety (humiliation/rejection and public performance fears), (3) harm avoidance (perfectionism and anxious coping), and (4) separation anxiety. It is designed for use with children eight to nineteen years of age, and has shown high test-retest reliability (March, Sullivan, \& Parker, 1999), internal reliability, and adequate convergent and divergent validity (March et al., 1997). Items on the MASC are rated on a 4-point Likert-type scale, ranging from 0 (never true for me) to 3 (often true for me.)

March et al. (1997) have shown the test-retest reliability of the MASC to be in the satisfactory to excellent range $(\mathrm{r}=.60-.93)$ and moderate correlations have been reported between the MASC and other psychometrically sound measures of social anxiety in children (RCMAS; $r=.63$ ). The internal consistency of the MASC has been found to be .90 for the total measure, with a range of .75 to .85 for the subscales (March et al., 1997). The total anxiety score was used as a measure of generalized child anxiety.

Behavioral and Social Self-Report Scale for Children (BSSRSC). The BSSRSC is a 36item questionnaire designed to assess symptoms of ADHD, conduct problems, and peer relationship problems in children, and was created for the larger school assessment and intervention study of which this project is a part. The measure is based on the Child Symptom Inventory, a behavior rating scale with items correspond to the symptoms of disorders defined by 
the DSM-IV. Items are rated on a 3-point scale, ranging from zero (never, or hardly ever), to two (most of the time, or always).

\section{Teacher Report Measures}

Strengths and Difficulties Questionnaire (SDQ). The SDQ (Goodman, Meltzer, \& Bailey, 1998 ) is a 25 -item questionnaire of both prosocial behavior and psychopathology which can be administered to parents and teachers of four to 16 year olds, and to 11 to 16 year olds themselves. The questionnaire measures difficulties in four main domains: emotional symptoms, conduct problems, hyperactivity-inattention, and peer problems, as well as prosocial behavior. Items are rated on a 3-point scale, ranging from "Not True," to "Definitely True," and severity/chronicity and impact of the child's behavior problems, if present, is marked on a separate scale ranging from 0 (No problem) to 6 (Extreme Problem). In a community sample of 7,984 children, the SDQ was able to identify $70 \%$ of individuals with conduct, hyperactivity, depressive, and certain anxiety disorders; however, fewer than 50\% of individuals with specific phobias, separation anxiety and eating disorders were successfully identified. Sensitivity is reduced with single-informant SDQ administration (Goodman, Ford, Simmons, Gatward, \& Meltzer, 2003). The level of agreement between clinical team diagnoses and diagnoses generated by the SDQ has shown a moderate to high, statistically significant correlation, ranging from 0.39 to 0.56 (Mathai, Anderson, \& Bourne, 2004). The present study used the teacher version of the SDQ.

\section{Sociometrics}

Sociometric nominations provide information regarding the relative degree to which a child is liked by his or her peer group. Sociometric nomination scores have been shown to be predictive of poor peer adjustment and at-risk behavior later in life (Parker \& Asher, 1987) and 
have been shown to be relatively stable across time and across new situations (Ironsmith \& Poteat, 1990; Coie \& Dodge, 1983; Coie \& Kupersmidt, 1983). Previous studies (Terry \& Coie, 1991) have reported base rates for the proportion of children within each sociometric status group, with children in the average status group comprising the largest proportion $(60 \%)$, followed by rejected children (13.5\%), popular children (12.9\%), controversial children (6.7\%), and neglected children (6.7\%).

\section{Playground Observations}

A behavioral coding scheme based on Strain and Timm (1974) was used to obtain ratings of positive and negative social interactions as well as solitary play. These are defined as follows:

a) Positive interaction: All vocalizations directed to another child excluding screams, shouts, cries, and whines; all cooperative responses involves with sharing an object; and hugs and holding hands.

b) Negative interaction: Screams, shouts, or other utterances that indicate rejecting and oppositional behavior; hit, pinch, kick, and "nonplaying" push or pull; grabbing objects from another child; and destroying construction of another child.

c) Solitary play: All solitary activity (excluding parallel play conducted between two children within two feet of one another)

For each category, scores were derived representing the percentage of intervals in which the behavior occurred.

\section{Procedure}

Participants were selected based on either self- or teacher-reports of anxiety and ADHD symptoms. The age group selected for the study was based on the lowest age at which children could complete the self-report measures used, and the upper limit reflected the highest age of 
children currently attending elementary school. If a child scored at or above the clinical cutoff on scores obtained from either self or teacher report, they were placed into the corresponding symptom group, creating four groups in total. One group consisted of 15 children scoring above the recommended clinical cutoff scores on anxiety symptoms (HiAnx group). T-scores of 65 or above on the Total Anxiety Scale of the MASC, or total scores of 18 or above on the SPAI-C, were used to identify children high in anxiety. A child was placed in the HiAnx group if they scored above the stated cutoffs on either measure.

The second group was created with children scoring one standard deviation above the mean $(M=7.27, S D=4.56)$ on ADHD symptoms ( HiADHD) using the BSSRC, or via a score of 7 or above on the teacher-report SDQ (Scores of 7-10 are considered "Abnormal" with $10 \%$ or less of a community sample falling in this range). The third group (Comorbid) consisted of 13 children who exceeded cutoff scores on both anxious symptoms (HiAnx) and ADHD symptoms (HiADHD). Finally, a comparison group comprised of 28 children was drawn at random from all children who did not display either significant anxiety or ADHD scores (Control).

Of the 422 consenting children, 93 were excluded (22\%) due to insufficient data necessary to place them in a symptom group. The final sample of 66 children was obtained by examining the data only of those children for whom freeplay observations were conducted.

\section{Sociometric Nominations}

Consenting participants were escorted individually outside the classroom during structured class time and were informed of the strict confidentiality of their responses to the interviewer. In the brief interview, the children were asked to name three classmates with whom he or she most liked to play ("Who do you like to play with most?") and three classmates whom he or she least liked to play ("Who do you like to play with the least?"). Children were allowed 
to freely nominate other children within their class, regardless of whether consent was obtained for the children they named. All students participating in the school assessment and intervention project provided sociometric nominations, not merely the children selected as the target sample for this study.

Nominations were obtained by a graduate student assistant, undergraduate assistants, and the principal investigator. Positive and negative nominations for each child were summed separately and converted to a proportion score in order to compare students across classrooms (i.e., number of nominations received divided by the number of nominators). These initial nominations were obtained in mid-March, which allowed ample time for the children to become familiar with others in their class. At the end of the interview, the children were reminded of the confidentiality of the responses given, and reminded not to tell anyone else in the class about what was said during the interview.

Children were classified into five distinct sociometric status groups described by Coie et al. (1982) using the statistical criteria presented by French and Waas (1985). Sociometric groups were based on the following criteria: (a) Popular children were those who received a high proportion of positive nominations $(\mathrm{SD}=.5$ above mean) and a low proportion of negative nominations ( $\mathrm{SD}=.5$ below mean); (b) Neglected children were classified as those who received a low proportion ( $\mathrm{SD}=.5$ below mean) of positive and negative nominations. (c) Rejected children were identified as having a high proportion of negative nominations $(\mathrm{SD}=.5$ above mean) and a low proportion of positive nominations ( $\mathrm{SD}=.5$ below mean). (d) Children in the controversial category were identified as having a high proportion of both positive and negative nominations ( $\mathrm{SD}=.5$ above mean for both). (e) Average status children made up the residual 
category of children who were neither actively liked nor actively disliked, consisting of students who failed to meet criteria for popular, neglected, rejected, or controversial status.

\section{Playground Observations}

Behavioral observations were conducted during recess for the final sample of 66 children. Observations were conducted by graduate and undergraduate students who were trained to an inter-rater reliability criterion of .85 or above. Observations consisted of 10 -second intervals over the course of ten minutes, with the occurrence of positive social interaction, negative social interaction, and solitary play coded within each interval for a total of 60 intervals for each observation period with a child. Observations were performed live and coded immediately on the playground. Recess periods were 25 minutes in length and observations covered the majority of free play time. Reliability checks were performed by research assistants and the principal investigator for a total of $23 \%$ of all observations. Percent agreement across all three codes (positive interaction, negative interaction, solitary play) using a point-by-point agreement ratio was $99 \%$, which measures agreement on each instance of the observed behavior. This method allowed for agreement to be evaluated on each observation interval and is more precise than a frequency ratio, which only evaluates agreements on totals. As the behavioral codes used were inclusive of all possible behavior, issues of non-occurrence agreement did not apply.

\section{Self-Report Questionnaires}

Data were collected by a team of graduate students who distributed the self-report measures to the children, supervised the procedure, and collected the measures from children when completed. Self-report questionnaires were administered in a group format to the entire class, and students were instructed to complete the reports on their own. A small number of students with reading difficulties had the questionnaire read to them by a graduate student. 
Children who did not have consent to participate were given an alternative activity to participate in, such as crossword puzzles and word searches.

Results

\section{Data Analysis Overview}

Analyses were conducted in a number of steps. First, descriptive statistics were performed to provide a summary of demographic characteristics of the sample and to determine if any differences were present between consenting and non-consenting children. Preliminary analyses were conducted on age, grade, and gender to determine whether there were any significant between group differences. Analyses of Variance (ANOVAs) were used to compare consent rate on child age, gender, and grade in school (Table 1). Consent rate did not differ significantly by age, $F(4,628)=2.04, n s$, grade, $F(2,635)=2.27$, ns, or gender, $F(1,634)=.91$, $n s$. Chi-Square analyses indicated no differences between groups on age, $\chi^{2}(2, N=636)=.95, p$ $=.62$.

Following these preliminary analyses, non-consenters were removed from the dataset, and symptom groups (HiAnx, HiADHD symptoms, Comorbid symptoms, and Control) were created based on successful completion of self-report measures, teacher report, and sociometric nominations (Table 2). In order to be included in the final sample, freeplay observation data were necessary (Table 3). Missing data (missing more than $20 \%$ of responses) on any of the above measures precluded a child from being placed into a symptom group. This resulted in 93 children out of the 422 who originally consented (22\%) being

excluded from inclusion of one of the four symptoms groups. Omnibus effects were limited due to low sample size in this study. However, inspection of the data yields interesting group comparisons. 
Kruskal-Wallis tests were conducted to examine between group differences on freeplay behavior. Following this, Mann-Whitney U-Tests were conducted to further evaluate pair-wise differences among the four groups. Due to the exploratory nature of the current study, a less stringent alpha level $(p<.10)$ was used to examine possible differences between groups.

Due to various factors within the school (absence, detention, distribution between classrooms) and time constraints, some data were missing. Children missing all self-report data were left as missing data points in analyses and no compensatory actions were taken (i.e., inserting a mean value). Some self-report data were missing due to item-nonresponse (the participant missed or refused to answer a specific question). If $80 \%$ or more of the data for that measure were present, mean imputation of that individuals mean score on the measure with missing data was used to recover missing values. Analyses were then performed on the data set as though the data had been completely observed. This was chosen over listwise deletion as eliminating data with missing responses may lead to a bias if the remaining cases are not representative of the entire sample. Although generally considered more appropriate than listwise or pairwise deletion, some disadvantages are present in using this method. Since the same value is being substituted for each missing case, this method artificially reduces the variance for the variable with missing data. At least $80 \%$ of data were present for all children who completed measures, therefore no participants were removed from analyses due to this criterion.

\section{Sociometric Status of Symptom Groups}

Of the 66 children in the final sample, ten were classified as popular (15.2\%), eight as rejected (12.1\%), one as controversial (1.5\%), four as neglected (6.1\%), and 43 as average $(65.2 \%)$ in social status (Table 4). Chi-Square analyses were conducted to examine the proportion of children within each symptom group who fell into each sociometric status 
category. Results indicated no significant difference between groups, $\chi^{2}(12, N=66)=10.74, p=$ .55 .

Freeplay Behavior of Symptom Groups

A Kruskal-Wallis test was conducted to evaluate differences among the four symptom groups (HiAnx, HiADHD, Comorbid, Control) on freeplay behavior rates (Positive, Negative, or Solitary). The results indicate a significant difference for rate of solitary behavior, $\chi^{2}(3, N=66)=$ $6.63, p=.085$. Comparisons for positive interaction, $\chi^{2}(3, N=66)=6.05, n s$, and negative interaction, $\chi^{2}(3, N=66)=3.85, n s$, were non-significant (Table 5).

\section{Follow up Tests on Freeplay Behavior Of Symptom Groups}

As an exploratory measure, Mann-Whitney U-Tests were conducted to evaluate pair-wise differences among the four symptom groups on rates of positive, negative, and solitary behavior. Results indicated a significant difference between the HiADHD group and Control group on Positive Interaction, $U=74, p=.028$, and Solitary behavior, $U=74, p=.026$ with HiADHD symptom children displaying significantly less positive interactions and significantly more solitary behavior than control children. No other group differences were found.

\section{Discussion}

This investigation was intended as a pilot study in the examination of social status and behavior associated with children who exhibit comorbid symptoms of anxiety and ADHD. Sociometric Status of Symptom Groups

Analyses were conducted to determine the social status of children within symptom groups (High Anxiety symptoms, High ADHD symptoms, Comorbid symptoms, and Control). Results suggested that social status did not differ as a function of symptom group. Contrary to the stated hypotheses, children who displayed elevated symptoms of anxiety (HiAnx) did not fall 
mainly in the neglected status group. Instead, children in the Comorbid group were more likely to be classified as neglected by their peers, and were not classified primarily in the rejected status group as was hypothesized. This finding may be due to a number of reasons. First, it must be noted that children classified as comorbid were rated by their teachers as having hyperactive/inattentive characteristics, while the children themselves reported high levels of anxiety (which is often associated with withdrawal and reticence in interpersonal situations). Thus, there may be a discrepancy between what behavior is exhibited within the classroom and how the child is interacting with peers and at what rate.

It may also be important to consider how these two opposing characteristics (being both anxious and hyperactive) are operating in relation to each other. The combination of these two behavioral extremes may be creating a unique way of interacting with other children. The negative behaviors these children display may be interfering with the ability to form close, positive friendships when the opportunity to form such friendships arises. Even if possible, feelings of anxiety may cause the child to be cautious, or even avoid attempting to form new friendships. This social deficit could affect and limit the amount of positive nominations they are receiving from their peers. There may be a low proportion of negative nominations received (despite these aggressive behaviors) because of a low frequency of interaction with other children, which may be a function of that child's anxiety and tendency to fear or withdraw from social interactions.

In combination, this unique interaction style may be leading to Comorbid children being neglected, rather than rejected, by the peer group. This can be contrasted to rejected children who do not report high levels of anxiety and may be less fearful of interacting with others. This higher 
rate of interaction may lead to more opportunities to create bad impressions or upset other children, and thus these children may be rejected by the peer group.

\section{Freeplay Behavior of Symptom Groups}

Analyses were conducted to examine the proportion of positive, negative, and solitary behavior children exhibited while interacting with peers at recess. Results suggested that all three elevated symptom groups exhibited a higher proportion of problem behavior on the playground, either through negative behavior or social isolation, than did controls. The results did not support the hypothesis that the high anxiety group would display the highest proportion of solitary behavior - instead, the highest proportion of solitary behavior was shown by the high ADHD symptom group, with highly anxious children showing the second highest level of solitary behavior. Also contrary to the stated hypothesis, children in the high ADHD symptom group did not display the highest proportion of negative behavior. Children in the comorbid Anxiety/ADHD group demonstrated the highest proportion of negative interaction with peers.

Taken together, these findings seem consistent with what is known about the behavior of children who show hyperactive and impulsive tendencies. Instead of choosing to spend time alone or in isolation from their peers, children in the High ADHD group may be alone because of their rejection from the peer group. The coding system used in this study did not allow for distinguishing between children who actively make the choice to play alone versus those who are forced to play alone because other children do not want to interact with them. Taking this into consideration, the finding that both these groups of children (HiAnx and HiADHD) display high levels of solitary behavior seems reasonable. It is important to make clear, however, that the two groups may spend time alone for very different reasons. Highly anxious children may play alone because of fear of approaching other children and the possibility of rejection or fear of being 
embarrassed, whereas rejected children may approach other peers and be refused the opportunity to play within the peer group as a consequence of their negative behavior.

Results did support the hypothesis that children in the comorbid Anxiety/ADHD symptom group would engage in higher rates of negative interaction during free-play observations. Although these children may be experiencing anxious symptoms internally, their outward expression of behavior still includes the negative interaction style associated with ADHD and results in outwardly expressed, observable negative behavior. Although it is still unclear how these two disorders operate in conjunction with each other, it may be that these children are experiencing anxiety after their impulsive behaviors occur, fearing the consequences of their actions and experiencing many of the somatic symptoms commonly associated with anxiety. Alternatively, the impulsive and aggressive behaviors may be the result of their anxiety if these children are acting out during an anxious moment to release the intense physiological and mental arousal experienced during intense fear or panic. The direction or causal pathway of these behaviors merit future research as they remain unknown.

\section{Limitations and Future Directions}

Limitations of this study should be noted. This study was intended to be an exploratory investigation of the behavior and social status of children who displayed comorbid anxiety and ADHD symptoms. The final sample size obtained was below what was intended and necessary for sufficient power to be reached, limiting the possibility of being able to detect effects even if they were present. Certain groups of children were especially underrepresented in the current study, most notably sociometrically neglected children (total of four children), and sociometrically controversial children (one child). The sample also consisted primarily of European-American children from middle-class socioeconomic backgrounds, limiting the ability 
to generalize to other populations. The low sample size and power limits the ability to draw any firm conclusions from this study. Time constraints of the elementary school year did not allow for further data to be collected for this study.

Another limitation involves the use of self-report measures with children. Although all measures except the Behavioral and Social Self-Report Scale for Children have been validated for use with children, some difficulties in understanding were encountered during data collection with children, making some responses questionable in their validity. Also, the predictive quality of the Strengths and Difficulties Questionnaire is not sufficient to make accurate statements regarding a child's psychological diagnoses. Although recent research has shown that diagnoses generated from the SDQ correlate moderately to highly with diagnoses made by clinicians (Mathai, Anderson, \& Bourne, 2004), the ability to make accurate statements regarding a child's behavioral problems would have been increased significantly had the self- and parent-report versions of the SDQ been used in conjunction with teacher report.

The nature of the children under examination led to difficulties during data collection, as children who displayed high rates of externalizing behavior were often in detention or held back from recess and/or lunchtime free-play opportunities. Some children scheduled to be observed were restricted from playing during recess on multiple occasions before they were actually observed, yet this fact is not reflected anywhere in the data collected. As a consequence of this, some children who may have otherwise shown negative behaviors may have never actually been observed, and those who were finally observed may have acted in a manner different from usual in fear of further punishment or restriction from recess. To a lesser extent, these children may have at some point noticed the observers and restricted their negative behavior under the 
assumption that behavioral coders were present to monitor their behavior specifically and perhaps punish them further or reported their behavior if a negative behavior occurred.

Future studies many benefit from using a larger, more culturally diverse sample in order to increase generalizability. Furthermore, a larger sample size will yield increased power to detect potentially significant findings. As the base rates for some categories in this study were low (most specifically sociometrically controversial children), a much larger sample may be necessary to obtain an adequate sample size for comparative analyses.

Longitudinal studies of children with comorbid Anxiety/ADHD symptoms and repeated observation of free-play behavior may lead to more definitive results by being able to track behavior and social interactions across time and environments. This type of research may help further clarify the direction of relations observed in this study, and monitor change, or lack of change, in the interaction patterns and relationships children have within their peer group.

\section{Conclusion}

The results of this study indicate that children who have anxious, ADHD, or comorbid symptoms experience difficulties in social relationships. Although statistically significant results were limited, examination of the data suggests that children experiencing the above problems may be isolated from their peers as a function of their anxiety or impulsive tendencies. Future research is necessary to more clearly understand how children who suffer from both anxiety and ADHD symptoms relate to other children, and how these two symptom constellations work in relation to each other to produce behaviors that may be considered negative by other children. If these children are identified at an early age, future clinical work may be directed at preventing the continuation of these negative behavioral patterns, and reducing the chances of these children being rejected and socially isolated by their classmates. 


\section{References}

Abikoff, H., \& Gittelman, R. (1985). The normalizing effects of methylphenidate on the classroom behavior of ADHD children. Journal of Abnormal Child Psychology, 13(1), $33-44$.

Abikoff, H., Jensen, P.S., Arnold, L.L., Hoza, B., Hechtman, L., Pollack, S., et al. (2002) Observed classroom behavior of children with ADHD: Relationship to gender and comorbidity. Journal of Abnormal Child Psychology, 30(4), 349-359.

Achenbach, T.M., \& Edelbrock, C.S. (1981). Behavioral problems and competencies reported by parents of normal and disturbed children aged four through sixteen. Monographs of the Society for Research in Child Development, 46(1), 82.

Asher, S.R., \& Dodge, K.A. (1986). Identifying children who are rejected by their peers. Developmental Psychology, 22(4), 444-449.

Asher, S.R., \& Hymel, S. (1981). Children's social competence in peer relations: Sociometric and behavioral assessment. In J.D. Wine, \& M.D. Smye (Eds.), Social competence (pp. 125-157). New York: Guilford Press.

Asher, S.R., \& Parker, J.G. (1989). Significance of peer relationship problems in childhood. In Barry H. Schneider \& Grazia Atilli (Eds.), Social competence in developmental perspective (pp.5-23). New York, NY: Kluwer Academic.

Asher, S.R., Singleton, L.C., Tinsley, B.R., Hymel, S. (1979). A reliable sociometric measure for preschool children. Developmental Psychology, 15(4), 443-444.

Asher, S.R., \& Wheeler, V.A. (1985) Children's loneliness: A comparison of rejected and neglected peer status. Journal of Consulting \& Clinical Psychology, 53(4), 500-505. 
Beidel, D.C., Turner, S.M., \& Fink, C.M. (1996). Assessment of childhood social phobia: Construct, convergent, and discriminative validity of the social phobia and anxiety inventory for children (SPAI-C). Psychological Assessment, 8(3), 235-240.

Beidel, D.C., Turner, S.M., Hamlin, K., \& Morris, T.L. (2000). The social phobia and anxiety inventory for children (SPAI-C): External and discriminative validity. Behavior Therapy, $31,75-87$.

Beidel, D.C., Turner, S.M., \& Morris, T.L. (1995). A new inventory to assess childhood social anxiety and phobia: The social phobia and anxiety inventory for children. Psychological Assessment, 7(1), 73-79.

Beidel, D.C., Turner, S.M., \& Morris, T.L. (1998). Manual for the social phobia and anxiety inventory for children. (SPAI-C). New York: Toronto.

Bell-Dolan, D.J., Foster, S.L., \& Sikora, D.M. (1989). Effects of sociometric testing on children's behavior and loneliness in school. Developmental Psychology, 25(2), 306-311.

Bell-Dolan, D.J., \& Wessler, A.E. (1994). Ethical administration of sociometric measures: Procedures in use and suggestions for improvement. Professional Psychology: Research \& Practice, 25(1), 23-32.

Biederman, J., Faraone, S.V., \& Chen, W.J. (1993). Social adjustment inventory for children and adolescents: Concurrent validity in ADHD children. Journal of the American Academy of Child \& Adolescent Psychiatry, 32(5), 1059-1064.

Biederman, J., Newcorn, J., \& Sprich, S. (1991). Comorbidity of attention deficit hyperactivity disorder with conduct, depressive, anxiety, and other disorders. American Journal of Psychiatry, 148(5), 564-577. 
Bukowski, W.M., \& Newcomb, A.F. (1985). Variability in peer group perceptions: Support for the "controversial" sociometric classification group. Developmental Psychology, 21(6), 1032-1038.

Cantrell, V.L., \& Prinz, R.J. (1985). Multiple perspectives of rejected, neglected, and accepted children: Relation between sociometric status and behavioral characteristics. Journal of Consulting and Clinical Psychology, 53, 884-889.

Charman, T., Pervova, I. (2001). The internal structure of the child depression inventory in Russian and UK schoolchildren. Journal of Youth \& Adolescence, 30(1), 41-51.

Cillessen, A.H., Bukowski, W.M., \& Haselager, G.J. (2000). Stability of sociometric categories. In A.H. Cillessen \& W.M. Bukowski (Eds.), Recent advances in the measurement of acceptance and rejection in the peer system, 75-93. San Francisco: Jossey-Bass.

Coie, J.D. (1990). Toward a theory of peer rejection. In S.R. Asher \& J.D. Coie (Eds.), Peer rejection in childhood (365-402). New York: Cambridge University Press.

Coie, J.D., \& Dodge, K.A. (1983). Continuities and changes in children's social status: A fiveyear longitudinal study. Merrill-Palmer Quarterly, 29(3), 261-282.

Coie, J.D., \& Dodge, K.A. (1988). Multiple sources of data on social behavior and social status in the school: A cross-age comparison. Child Development, 59(3), 815-829.

Coie, J.D., Dodge, K.A., \& Coppotelli, H. (1982). Dimensions and types of social status: A cross-age perspective. Developmental Psychology, 18(4), 557-570.

Coie, J.D., Dodge, K.A., Terry, R. \& Wright, V. (1991). The role of aggression in peer relations: An analysis of aggressive episodes in boys' play groups. Child Development, 62(4), 812826. 
Coie, J.D., \& Kupersmidt, J.B. (1983). A behavioral analysis of emerging social status in boy's groups. Child Development, 54(6), 1400-1416.

Coie, J.D., Terry, R., Lenox, K., \& Lochman, J. (1995). Childhood peer rejection and aggression as predictors of stable patterns of adolescent disorder. Development \& Psychopathology, 7(4), 697-713.

Craighead, W.E., Smucker, M.R., Craighead, L.W., \& Ilardi, S.S. (1998). Factor analysis of the children's depression inventory in a community sample. Psychological Assessment, 10(2), 156-165.

Crick, N.R. (1996). The role of overt aggression, relational aggression, and prosocial behavior in the prediction of children's future social adjustment. Child Development, 67(5), 23172327.

DeApodaca, R.F., \& Cowen, E.L. (1982). A comparitive study of the self-esteem, sociometric status, and insight of referred and nonreferred school children. Psychology in the Schools, 19, 394-401.

DeRosier, M.E., \& Thomas, J.M. (2003). Strengthening sociometric prediction: Scientific advances in the assessment of children's peer relations. Child Development, 74(5), 13791392.

Dodge, K.A. (1983). Behavioral antecedents of peer social status. Child Development, 54(6), 1386-1399.

French, D.C., \& Waas, G.A. (1985). Behavior problems of peer-neglected and peer rejected elementary age children: Parent and teacher perspectives. Child Development, 51(1), 246252. 
Foster, S.L., \& Ritchey, W.L. (1979). Issues in the assessment of social competence in children. Journal of Applied Behavior Analysis, 12, 625-638.

Goodman, R., Ford, T., Simmons, H., Gatward, R., \& Meltzer, H. (2003). Using the strength's and difficulties questionnaire (SDQ) to screen for child psychiatric disorders in a community sample. International Review of Psychiatry, 15(1-2), 166-172.

Goodman, R., Meltzer, H., \& Bailey, B. (1998).The strengths and difficulties questionnaire: A pilot study on the validity of the self-report version. European Child \& Adolescent Psychiatry, 7(3), 125-130.

Goodwin, R.D., Fergusson, D.M., \& Horwood, J.L. (2004). Early anxious/withdrawn behaviours predict later internalising disorders. Journal of Child Psychology and Psychiatry, 45, $874-883$.

Hartup, W.W. (1989). Social relationships and their developmental significance. American Psychologist, 44, 120-126.

Hatzichristou, C., \& Hopf, D. (1996). A multiperspective comparison of peer sociometric status groups in childhood and adolescence. Child Development, 67(3), 1085-1102.

Hayvren, M., \& Hymel, S. (1984). Ethical issues in sociometric testing: Impact of sociometric measures on interaction behavior. Developmental Psychology, 20(5), 844-849.

Inderbitzen, H.M., Walters, K.S., \& Bukowski, A.L. (1997). The role of social anxiety in adolescent peer relations: Differences among sociometric status groups and rejected subgroups. Journal of Clinical Child Psychology, 4, 338-348.

Ironsmith, M., \& Poteat, G.M. (1990). Behavioral correlates of preschool sociometric status and the prediction of teacher ratings of behavior in kindergarten. Journal of Clinical Child Psychology, 19(1), 17-25. 
Iverson, A.M., Barton, E.A., \& Iverson, G.L. (1997). Analysis of risk to children participating in a sociometric task. Developmental Psychology, 33(1), 104-112.

Iverson, A.M., \& Iverson, G.L. (1996). Children's long-term reactions to participating in sociometric assessment. Psychology in the Schools, 33(2), 103-112.

Keane, S.P., \& Calkins, S.D. (2004). Predicting kindergarten peer social status from toddler and preschool problem behavior. Journal of Abnormal Child Psychology, 32(4), 409-423.

Kovacs, M. (1992). Children’s Depression Inventory. New York: Multi-Health Systems.

Ladd, G.W. (1983). Social networks of popular, average, and rejected children in school settings. Merrill-Palmer Quarterly, 29(3), 283-307.

Ladd, G.W., \& Burgess, K.B. (1999). Charting the relationship trajectories of aggressive, withdrawn, and aggressive/withdrawn children during early grade school. Child Development, 70(4), 910-929.

Ladd, G.W., Price, J.M., \& Hart, C.H. (1988). Predicting preschoolers' peer status from their playground behaviors. Child Development, 59(4), 986-992.

La Greca, A.M., \& Stone, W.L. (1993). Social anxiety scale for children-revised: Factor structure and concurrent validity. Journal of Clinical Child Psychology, 22, 17-27.

Laird, R.D., Jordan, K.Y., Dodge, K.A., Petit, G.S., \& Bates, J.E. (2001). Peer rejection in childhood, involvement with antisocial peers in early adolescence, and the development of externalizing behavior problems. Development \& Psychopathology, 13(2), 337-354.

March, J.S., Parker, J.D., Sullivan, K., Stallings, P., \& Conners, C.K. (1997). The Multidimensional Anxiety Scale for Children (MASC): Factor structure, reliability, and validity. Journal of the American Academy of Child \& Adolescent Psychiatry, 36(4), 554565. 
March, J.S., Sullivan, K., Parker, J. (1999). Test-retest reliability of the Multidimensional Anxiety Scale for Children. Journal of Anxiety Disorders, 13(4), 349-358.

Mathai, J., Anderson, P., Bourne, A. (2004). Comparing psychiatric diagnoses generated by the Strengths and Difficulties Questionnaire with diagnoses made by clinicians. Australian and New Zealand Journal of Psychiatry, 38, 639-643.

Morris, T.L., \& Masia, C.L. (1998). Psychometric evaluation of the Social Phobia and Anxiety Inventory for Children: Concurrent validity and normative data. Journal of Clinical Child Psychology, 27(4), 452-458.

Newcomb, A.F., \& Bukowski, W.M. (1983). Social impact and social preference as determinants of children's peer group status. Developmental Psychology, 19(6), 856-867.

Newcomb, A.F., Bukowski, W.M., \& Pattee, L. (1993). Children's peer relations: A metaanalytic review of popular, rejected, neglected, controversial, and average sociometric status. Psychological Bulletin, 113(1), 99-128.

Newcorn, J.H., Miller, S.R., Ivanova, I., Schulz, K.P., Kalmar, J., Marks, D.J., et al. (2004). Adolescent outcome of ADHD: Impact of childhood conduct and anxiety disorders. CNS Spectrums, 9(9), 668-678.

Ollendick, T.H., Weist, M.D., Borden, M.C., \& Greene, R. (1992). Sociometric status and academic, behavioral, and psychological adjustment: A five-year longitudinal study. Journal of Consulting \& Clinical Psychology, 60(1), 80-87.

Parker, J.G., \& Asher, S.R. (1987). Peer relations and later personal adjustment: Are lowaccepted children at risk? Psychological Bulletin, 102(3), 357-389.

Pliszka, S.R. (1989). Effect of anxiety on cognition, behavior, and stimulant response in ADHD. Journal of the American Academy of Child \& Adolescent Psychiatry, 28(6), 882-887. 
Pliszka, S.R. (1992). Comorbidity of attention-deficit hyperactivity disorder and overanxious disorder. Journal of the American Academy of Child \& Adolescent Psychiatry, 31(2), 197-203.

Rubin, K.H., Daniels-Beirness, T., \& Hayvren, M. (1982). Social and social-cognitive correlates of sociometric status in preschool and kindergarten children. Canadian Journal of Behavioural Science, 14(4), 338-349.

Rubin, K.H., LeMare, L.J., \& Lollis, S. (1990). Social withdrawal in childhood: Developmental pathways to peer rejection. In S.R. Asher \& J.D. Coie (Eds.). Peer Rejection in Childhood (217-249). New York, NY: Cambridge University Press.

Rubin, K.H., Hymel, S., LeMare, L.J., \& Rowden, L. (1989). Children experiencing social difficulties: Sociometric neglect reconsidered. Canadian Journal of Behavioural Science, 21, 94-111.

Strauss, C.C., Lahey, B.B., Frick, P., Frame, C.L., \& Hynd, G.W. (1988) Peer social status of children with anxiety disorders. Journal of Consulting \& Clinical Psychology, 56(1), $137-141$.

Strain, P.S., \& Timm, M.A. (1974). An experimental analysis of social interaction between a behaviorally disordered preschool child and her classroom peers. Journal of Applied Behavior Analysis, 7(4), 583-590.

Sullivan, Harry S. (1953). The interpersonal theory of psychiatry. New York, NY: Norton.

Terry, R., \& Coie, J.D. (1991). A comparison of methods for defining sociometric status among children. Developmental Psychology, 27(5), 867-880. 
Timbremont, B., Braet, C., \& Dressen, L. (2002). Assessing depression in youth: Relation between the Children's Depression Inventory and a structured interview. Journal of Clinical Child \& Adolescent Psychology, 33(1), 149-157.

Vaughn, B.E., \& Langlois, J.H. (1983) Physical attractiveness as a correlate of peer status and social competence in preschool children. Developmental Psychology, 19(4), 561-567.

Williams, B.T.R., \& Gilmour, J.D. (1994). Sociometry and peer relationships. Journal of Child Psychology and Psychiatry, 35(6), 997-1013. 
Table 1.

Symptom Group Distribution Across Sociometric Status ( $\mathrm{N}=66)$

\begin{tabular}{lccccc}
\hline & \multicolumn{2}{c}{ Symptom Group } & & \\
Status Group & HiAnx & HiADHD & Comorbid & Control & Total \\
\hline Popular & 3 & 2 & 3 & 2 & 10 \\
Rejected & 2 & 3 & 0 & 3 & 8 \\
Controversial & 0 & 0 & 0 & 1 & 1 \\
Neglected & 0 & 0 & 1 & 3 & 4 \\
Average & 10 & 5 & 9 & 19 & 43 \\
Total & 15 & 10 & 13 & 28 & 66 \\
\hline
\end{tabular}


Table 2.

One-Way Analysis of Variance for Effects of Age, Gender, and Grade on Consent Rate (N=638)

\begin{tabular}{lcccc}
\hline Variable and Source & df & SS & MS & F \\
\hline Child Age (years) & & & & \\
$\quad$ Between Groups & 4 & 4.40 & 1.10 & .54 \\
$\quad$ Within Groups & 628 & 339.6 & & \\
& & & & .04 \\
Child Gender & & & .50 & \\
$\quad$ Between Groups & 1 & .50 & .55 & \\
$\quad$ Within Groups & 634 & 348.37 & & .04 \\
& & & 1.77 & .52 \\
Child Grade & & & & \\
$\quad$ Between Groups & 2 & 3.53 & & \\
$\quad$ Within Groups & 635 & 331.98 & & \\
\hline
\end{tabular}


Table 3.

Means and Standard Deviations on Entire Sample $(\mathrm{N}=638)$ for Anxiety and ADHD Measures

\begin{tabular}{|c|c|c|c|c|c|c|c|c|}
\hline \multirow[b]{2}{*}{ Measure } & \multicolumn{2}{|c|}{ Hi-Anxiety } & \multicolumn{2}{|c|}{ Hi-ADHD } & \multicolumn{2}{|c|}{ Comorbid } & \multicolumn{2}{|c|}{ Control } \\
\hline & $\underline{\mathrm{M}}$ & $\underline{\mathrm{SD}}$ & $\underline{\mathrm{M}}$ & $\underline{\mathrm{SD}}$ & $\underline{M}$ & $\underline{\mathrm{SD}}$ & $\underline{M}$ & $\underline{\mathrm{SD}}$ \\
\hline SPAI-C & 23.04 & 5.25 & 7.89 & 5.20 & 23.51 & 4.99 & 8.58 & 5.28 \\
\hline MASC & 53.02 & 18.82 & 31.13 & 17.39 & 59.20 & 18.70 & 33.85 & 14.55 \\
\hline $\begin{array}{l}\text { SDQ ADHD } \\
\text { scale (Teacher) }\end{array}$ & 2.52 & 1.10 & 4.64 & 2.71 & 4.0 & 2.20 & 2.54 & 1.24 \\
\hline $\begin{array}{l}\text { BSRC ADHD } \\
\text { scale (Self) }\end{array}$ & 7.22 & 2.54 & 13.65 & 4.33 & 14.21 & 3.9 & 5.23 & 2.93 \\
\hline
\end{tabular}


Table 3.

Means and Standard Deviations on Final Sample $(\mathrm{N}=66)$ for Anxiety and ADHD Measures

\begin{tabular}{|c|c|c|c|c|c|c|c|c|}
\hline \multirow[b]{2}{*}{ Measure } & \multicolumn{2}{|c|}{ Hi-Anxiety } & \multicolumn{2}{|c|}{$\underline{\mathrm{Hi}-\mathrm{ADHD}}$} & \multicolumn{2}{|c|}{ Comorbid } & \multicolumn{2}{|c|}{ Control } \\
\hline & $\underline{\mathrm{M}}$ & $\underline{\mathrm{SD}}$ & $\underline{\mathrm{M}}$ & $\underline{\mathrm{SD}}$ & $\underline{\mathrm{M}}$ & $\underline{\mathrm{SD}}$ & $\underline{\mathrm{M}}$ & $\underline{\mathrm{SD}}$ \\
\hline SPAI-C & 25.14 & 6.31 & 8.51 & 5.98 & 24.0 & 4.62 & 8.81 & 4.90 \\
\hline MASC & 61.19 & 23.77 & 33.36 & 15.10 & 56.06 & 17.56 & 34.39 & 16.38 \\
\hline $\begin{array}{l}\text { SDQ ADHD } \\
\text { scale (Teacher) }\end{array}$ & 2.36 & 1.15 & 4.30 & 2.67 & 4.46 & 1.98 & 3.06 & 1.43 \\
\hline $\begin{array}{l}\text { BSRC ADHD } \\
\text { scale (Self) }\end{array}$ & 7.42 & 2.71 & 14.91 & 3.55 & 14.72 & 3.07 & 5.18 & 3.25 \\
\hline
\end{tabular}


Table 5 .

$\underline{\text { Kruskal-Wallis Test of Behavior Rates in Freeplay Observation }}$

\begin{tabular}{lccc}
\hline Variable and Source & $\mathrm{M}$ & $\mathrm{SD}$ & $\chi^{2}$ \\
\hline & & & \\
Freeplay Behavior & 77.03 & 26.94 & 6.05 \\
$\quad$ Positive & 3.42 & 4.94 & 3.85 \\
Negative & 19.30 & 26.80 & 6.63 \\
Solitary & & \\
\hline
\end{tabular}

